\title{
PROMIS Pain Rating Scale
}

National Cancer Institute

\section{Source}

National Cancer Institute. PROMIS Pain Rating Scale. NCI Thesaurus. Code C121723.

A linear analogue scale for the subjective scoring of a person's average pain rating for the past seven days that ranges from 0: No pain to 10: Worst imag inable pain. 